\title{
Entre a memória e o esquecimento: modos de compreender a história
}

Between memory and forgetfulness: ways of understanding history

\section{lara Lis Schiavinatto \\ Professora no Departamento de Multimeios, Mídia e Comunicação da Universidade Estadual de Campinas (UNICAMP - Campinas/Brasil) e-mail: iaralis@uol.com.br}

\section{Resumo}

Este artigo busca comentar pontualmente a pesquisa coordenada por João Paulo Pimenta, considerando as relações entre passado e presente e as perspectivas da história pública presentes nessa pesquisa.

\section{Abstract}

This article aims at giving some brief comments about the research coordinated by João Paulo Pimenta. It seeks to point out the relationships between the past and the present and future prospects of public history contained in this research.

\section{Palavras-chave}

Independência do Brasil, história pública, história intelectual.

Keywords

Independence of Brazil, public history, intellectual history. 
Apenas a fim de situar o leitor, além de artigos na Almanack: PIMENTA, João Paulo Garrido. $A$ Independência do Brasil e o liberalismo português: um balanço da produção acadêmica. HIb: Revista de História Iberoamericana. Santiago, v.1, 2008, p.70-105; $A$ independência do Brasil como uma revolução: história e atualidade de um tema clássico. História da historiografia. Ouro Preto, n.3, 2009, p.53-82.

2

Ver CHALOUB, Sidney e FONTES, Paulo. História social do trabalho, história pública. Perseu. São Paulo, n.4, 2009. p.219-228. Disponível em: http://novo.fpabramo.org.br/sites/default/files/8. perseu4.chalhoubfontes.historia.pdf.

3

É possivel acessar o trailler de Verdade 12.528 em https://www.youtube.com/ watch?v=qoG4_4qv-Zk e o documentário de Maria Oliveira e Marta Nehring em https://www. youtube.com/watch?v=qoG4_4qv-Zk.
Antes de tudo, gostaria de agradecer o convite da Almanack para conversar sobre essa pesquisa centrada nos modos de compreender a Independência do Brasil, na cidade de São Paulo de nossos dias. Quero muito cumprimentar o trabalho de equipe valoroso liderado por João Paulo Pimenta, conhecido estudioso interessado em matizar as inteligibilidades, historicamente engendradas, acerca da Independência. ${ }^{1}$

Em sua abordagem, a pesquisa articula cultura política, cultura de história - para ficar no termo rigorosamente escolhido pelos autores que engloba e expande a consciência histórica - e formas de recordar. Ela aciona uma noção de história pública, me parece, ao pressupor múltiplas possibilidades de instrumentos e espaços de produção, circulação, difusão, recepção e consumo do conhecimento histórico na diacronia e/ ou em simultâneo na sociedade contemporânea. A história pública não se constitui em monopólio do historiador de ofício, sendo que o cidadão, leigo em história, participa e atua de várias maneiras e em graus distintos da elaboração desse saber e sua divulgação.

0 cerne da pesquisa realizada por João Paulo Pimenta e sua equipe indaga as noções imputadas à Independência do Brasil por diversos sujeitos sociais em suas variadas ordens discursivas, algumas com forte entrada e repercussão no espaço público. Tais noções partilham, ao fim e ao cabo, de pontos de vista em comum. Em geral, a Independência é compreendida como um fato histórico crucial do ideário nacional. Lembro que tal fato estaria conjugado no senso comum, quase num corolário, a outros fatos da nação de primeira grandeza, tais como o Descobrimento, a Abolição da Escravidão, a Proclamação da República. Em conjunto, teleologicamente encadeados de trás para frente, esses fatos recontariam naturalmente a história do Brasil. A data aqui estaria alçada à condição de lugar de memória da nação e, ao ser ritualizada, conferiria valor e sentido à vida daqueles que a executam.

Surpreende, contudo, nos resultados levantados pela pesquisa, a estável e conservadora compreensão da Independência. Lembro, em contraponto, os recentes deslocamentos de sentido da Abolição da Escravidão desde seu Centenário em 1988, quando despontou uma vigorosa interlocução entre a historiografia, os movimentos sociais e as realidades vividas acerca do trabalho compulsório. ${ }^{2}$ Acrescente-se a isso a percepção, neste ano de 2014, da reordenação da noção de ditadura militar no Brasil. Na vertente da cultura de história, difunde-se no agora, por ocasião dos 50 anos do golpe civil-militar, uma mudança nos significados da ditadura civil-militar nos vários encontros de história voltados ao debate do tema, mas também em outros espaços de produção de conhecimento histórico - do audiovisual aos movimentos políticos e sociais, donde o tema da juventude se sobressai, seja pelos depoimentos prestados por uma geração que é filha de perseguidos políticos, seja porque jovens realizadores assinam documentários, a exemplo de Verdade 12.528 e 15 Filhos. $^{3}$ Contrasta aqui a permanência e o grau de homogeneização da compreensão da Independência na cidade de São Paulo, com poucos abalos e tensões. Pode-se observar, por sua vez, que a Abolição da Escravidão e a Ditadura trazem à baila experiências históricas traumáticas que negam as convenções dos direitos humanos e evocam o dever de memória e a política de reparação - entendidos como processos potencializados no presente com suas demandas sociais e políticas sobre o passado. No bojo desses processos, é possivel perceber noções comuns partilhadas por historiadores de ofício e um público maior (por exemplo, a necessidade da existência da Comissão 
4

Essa repetição contrasta com a pesquisa feita por Cecília Helena de Salles Oliveira a propósito da visitação do Museu Paulista da USP, bem conhecido como Museu do Ipiranga, no 7 de setembro - data intrinsecamente vinculada ao Museu. Das entrevistas feitas com os visitantes, surge um sujeito ativo que escolhe ir ao Museu nesse dia com a familia e indaga os significados do museu e, em certa medida, alude ao teor da data civica e da Independência. SALLES OLIVEIRA, Cecilia Helena de. Museu Paulista: espaço de evocação do passado e reflexão sobre a história. Anais do Museu Paulista. São Paulo, Nova Série v.10/11, 2002/2003, p.105-126.

5

Canclini descreve com certa picardia: Você está dirigindo o carro enquanto ouve um áudio-livro e é interrompido por uma ligação no celular. Ou você está em casa, sentado numa poltrona, com o romance que acabou de comprar, enquanto na televisão ligada à espera do noticiário passa um anúncio sobre as novas funções do Ipod. Você se levanta e vai até o computador para ver se compreende essas novidades que não estão mais nas enciclopédias de papel e, de repente, percebe quantas vezes, mesmo para procurar dados sobre outros séculos, recorre a esses novos patrimônios da humanidade que se chamam Google e Yahoo. GARCÍA CANCLINI. Néstor. Leitores, Espectadores e Internautas. São Paulo: Iluminuras, Observatório Itaú Cultural, 2008.p. 11.

6

RICOEUR, Paul. A Memória, A História, 0 Esquecimento. Campinas: Ed. UNICAMP, 2007. da Verdade) e aquelas mais refratárias (a dificuldade em chamar de ditador algum presidente brasileiro do periodo de 1964-85, na direção de forma análoga da nomeação de Pinochet no Chile). Destaco, em suma: de um lado, certa fixidez de uma interpretação conservadora de Independência na cidade de São Paulo no tempo presente; por outro, não há uma relação prefixada, unidirecional ou hierárquica entre os historiadores de ofício e o cidadão leigo em história. Tampouco a permanência do significado do evento está a priori garantida. Cabe indagar as balizas dessa estabilidade e regularidade de uma narrativa conservadora da Independência exposta pela pesquisa. ${ }^{4}$

0 debate a respeito da Independência da nação concorre para a constituição de comunidades imaginadas com valores e histórias partilhadas. Aqui, o marco cronológico imbrica-se ao critério biográfico-anedótico para dizer e significar a Independência. 0 marco cronológico, sintetizado no 7 de setembro de 1822, converteu-se em data histórica enaltecida desde a década de 1820 e em feriado nacional, via de regra, celebrado. A narrativa, ao entrelaçar data histórica e critério biográfico-anedótico, acaba por asseverar a mitologia da fundação da nação que adquire cor, performance, gestualidade, adjetivos, palavras, lemas para o bem e para o mal. Enfim, a vivacidade da narrativa envolve o leitor-ouvinte-espectador-internauta - pois não se pode negar ou subestimar essa condição contemporânea do sujeito ${ }^{5}$ de frequência múltipla e simultânea, cotidiana e amiúde às mídias hibridizadas e aos equipamentos culturais em expansão e cada vez mais midiatizados.

0 texto de João Paulo e sua equipe mostra a maciça repetição de uma mesma narrativa a respeito da Independência em filmes, séries televisivas, quadrinhos, livros de difusão, livros didáticos, nas falas dos entrevistados na rua e, friso, a preocupante dificuldade de profissionais, em geral jornalistas e possivelmente parte dos espectadores, em escutar os comentários dos especialistas da área com abordagens historiograficamente diferentes sobre o tema em programas disponibilizados online. A narrativa da Independência parece tão incrustada a determinados topos retórico regidos pela cronologia, anedota, biografia, que, uma vez evocados, de imediato um mecanismo, bastante automatizado, a (re)cita. Repete-se, com uma passividade incômoda, uma narrativa já cristalizada na sociedade.

Por definição, memória é esquecimento e, ao mesmo tempo, é uma operação. ${ }^{6}$ Ao se dizer essa narrativa da Independência, ela se converte num modo de rememoração dessa experiência. Primeiro, converte o processo de autonomização numa data cívica e engessada. Concorre também para o esquecimento das múltiplas experiências do amplo e dinâmico processo de autonomização do Brasil, enquanto corpo político no mundo luso-brasileiro vincado pelas várias questões e práticas de poder. 0 esquecimento aqui opera de várias formas; por exemplo, através do silenciamento dos diversos sujeitos sociais e étnicos em suas elaboradas disputas no emergente campo do político - enquanto instância do real. A repetição automática dessa narrativa calcada em critérios biográficos, anedóticos, cronológicos tende a esclerosar a experiência política da fundação de uma coletividade. Dessa maneira, esvazia a força das experiências lá vividas capazes de nos dizer em nosso presente e concorrer para a reelaboração das balizas da vida coletiva no contemporâneo, ao menos para instigar nossa imaginação. Esvanecem-se os elementos radicais e cortantes dessas experiências de autonomização do Brasil no âmbito do cidadão comum. Esse cânone narrativo esvazia a importância e a intrincada trama da constitui- 
7

GINZBURG, Carlo. Exprasis e citação. In: $A$ Micro-História e outros Ensaios. Lisboa: Difel, 1991, p.215-232; HOLLY, Michael Ann. Historical Imagination and the Retoric of the Image. New York: Cornel University, 1996.

8

Disponibilizado em https://www.youtube. com/watch?v=wk9ZE7C9P58. Acesso em 12 de outubro de 2014

9

GINZBURG, Carlo. Medo, Reverência, Terror. São Paulo: Cia das Letras, 2014. ção dos espaços públicos, nesse período entremeado por debates acerca dos modos de governar e obedecer em espaços de poder distintos. Essa trama implicava os processos de constituição desses sujeitos e os ideários então criados, inventados, mobilizados. Esse cânone narrativo esconde questões fundamentais e, ato contínuo, esclerosa a história do processo da independência, amarrando-o a uma cronologia diminuta em torno do 7 de setembro e a meia dúzia de protagonistas, condenados ao mesmo script. Tratam-se, assim, de operações de memória e de esquecimento, entrelaçadas. A narrativa reconta uma história política, no entanto, ela tem um efeito contrário ao despolitizar a experiência da independência, na medida em que todo roteiro histórico já está traçado e que toda a origem da nação se resume a meia dúzia de ações, interesses, perfis pessoais, fatos. Não à toa, essa narrativa histórica, promovida em parte pelo Estado, mantida aqui e acolá por historiadores e por interesses mercadológicos, acarreta numa espécie de indiferença social quanto à repetição convencional da fundação da nação.

Boa parte dessa vivacidade da narrativa reside em artifícios considerados importantes para a escrita da história ao lançar mão da cronologia e da biografia. Essa vivacidade atrela-se a evidências do passado, funcionando como uma ekfrasis. ${ }^{7}$ Há uma inteligência no embasamento dessa narrativa ao se valer de recursos metodológicos básicos ditados pela memória disciplinar da história (cronologia e biografia). Astuciosamente manejados, esses recursos tendem a naturalizar a narrativa, como se ela não derivasse de nenhum ponto de vista ou tivesse algum compromisso na enunciação, dotando-a de um senso de neutralidade e objetividade. Tal vivacidade assenta-se em determinados elementos literários apontados no texto de João Paulo Pimenta (os excessos da família dos Bragança evidenciados na gula de D. João, na luxúria de Carlos Joaquina, no destempero de D. Pedro). $E_{1}$ acrescento, no caso do audiovisual em particular, há um investimento na repetição desses mesmos elementos dramáticos e a direção de arte escolhe mostrar lugares, paisagens, figurinos, maquiagens, cenários, objetos que materializam o tempo de outrora da independência insistindo em expedientes visuais que reforçam esse cânone narrativo sobre a Independência.

A cultura material, sob a batuta da direção de arte, reitera essa vivacidade do drama histórico. No filme Carlota Joaquina (1995), ${ }_{1}^{8}$ a direção de arte delineia três monarquias em suas respectivas cortes - Madri, Lisboa, Rio de Janeiro -, recorrendo a uma iconografia política ${ }^{9}$ a moldar as protagonistas e os lugares dessa trama através do abuso do vermelho e do jogo do claro e escuro em Madri e em Lisboa, e aposta na claridade dos trópicos. Lá, um excesso de roupas; aqui uma falta delas inclusive com uma cartela cromática quente. As declarações frequentes da diretora do filme, Carla Camurati, sobre sua pesquisa em acervos brasileiros e internacionais a respeito da Independência, avalizavam no limite a realidade do filme, reforçando essa iconografia política na medida em que a naturalizava. Carlota Joaquina cultua o começo da nação com a transferência da corte portuguesa para 0 Rio de janeiro. Esse culto do momento de origem foi atrelado na época do seu lançamento e exibição ao que se denomina Retomada do Cinema $\mathrm{Na-}$ cional no contexto político e cultural do governo Collor, o qual intensifica o discurso de origem do filme para boa parte do público e da crítica. Trocando em miúdos, o filme reitera essa narrativa cristalizada sobre a Independência e, assim, adquire sentidos políticos ao se articular com a necessidade de se produzir cinema no Brasil no contexto do governo Collor. 
Sobre os significados do herói nacional esquartejado, ver: LARA, Silvia H. Tiradentes e a nação esquartejada. In: CUNHA, Maria Clementina Pereira da. Pátria Amada, Esquartejada. São Paulo: Secretaria Municipal de Cultural. 1992, p.19-28.
Em outros dois filmes, essa vivacidade reaparece com argumentos afins. De um lado, atrela-se à celebração de datas nacionais (a Inconfidência Mineira e a Independência do Brasil), ao figurar as razões e a trama histórica do Sesquicentenário da Independência enaltecido em 1972 pelo governo Médici. Por outro, a direção de arte, me parece, desempenha novamente um papel relevante, a fim de assemelhar-se com fidelidade ao tempo recordado, através da ambiência histórica, buscando convencer o espectador que assiste em simultâneo ao filme e à celebração cívica. De certa maneira, há uma espécie de justaposição de camadas de significação a consolidar a veracidade histórica do filme. Em Independência ou Morte (1972), o drama parece mais folhetinesco ao juntar o casal consagrado pelas telenovelas de hegemônico sucesso no período (os atores Glória Meneses e Tarcisio Meira emprestavam seu casamento real e comum na teledramaturgia para sugerir o amor autêntico entre D. Pedro e a Marquesa de Santos) em locações nas quais ecoavam uma arquitetura colonial, em função do enquadramento de câmera ou pela estudada composição de figurinos. Nesse caso, o filme dramatizava, em 7 de setembro de 1972, os motivos mais altaneiros para a celebração do Sesquicentenário da Independência. Cabe assinalar que os muitos materiais didáticos, contemplando os de apoio didáticos, produzidos para esse mesmo fim, tiveram ampla circulação no período: almanaques, calendários, enciclopédias, revistas destinadas aos jovens, publicações de caráter cívico distribuídas no ambiente escolar para professores e estudantes.

Já Os Inconfidentes (1972) segue esse critério biográfico com uma câmera mais distanciada, reproduzindo longas falas extraídas dos autos da devassa mineira e da literatura de Cecília Meirelles. Ele acompanha a situação torturante dos inconfidentes entre serem delatados, delatarem, sentenciados, inocentados, punidos, executados. 0 filme não deixava de aludir a uma situação vivida na sociedade de então. No final do filme, ao tratar da execução do herói Tiradentes perfilado à figura do Cristo, Os Inconfidentes faz uma passagem sutil no plano fílmico, mas forte do ponto de vista da narrativa, entre o tempo dos inconfidentes e o tempo de agora. 0 filme coloca uma massa juvenil e estudantil na cidade de Ouro Preto para celebrar civicamente no agora a morte do herói do passado sob a

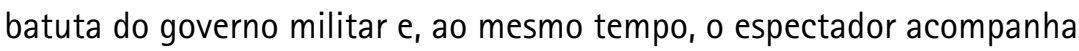
em paralelo, pela linguagem diegética, a execução e morte de Tiradentes. 0 filme ritualiza a figura do herói com uma parada cívico-militar em Ouro Preto, mostrada sob o formato de cinejornal em preto-e-branco com uma locução em tom oficial e pautada pelo factual. Essa passagem engata 0 antes dos inconfidentes e o agora do filme num tom distante que suscita um estranhamento no espectador. Pela sua raridade, esse efeito de estranhamento na época tinha maior capacidade de impactar o espectador do que hoje. A execução de Tiradentes reverbera durante todo o filme na carne batida e esquartejada que abre e fecha o filme. ${ }^{10}$ Nesses dois filmes, a relação instaurada entre o tempo de antes e o tempo presente parece procurar ilustrar um e outro, retratando o passado recortado com uma suposta objetividade irrefutável.

Se minha argumentação procede, posso sugerir que essa narrativa tão cristalizada sobre a independência, mapeada pela pesquisa capitaneada por João Paulo Pimenta, carrega anacronismos históricos distintos que, por sua vez, podem suscitar variações de sentido acerca da Independência e seus termos correlatos - liberdade, entre eles. 0 anacronismo é produtor 
de sentido histórico no social, não se restringindo apenas ao erro e pode ocorrer com mediações distintas entre as temporalidades do passado e do presente, afetando a percepção dessas temporalidades. Carlota Joaquina e Independência ou Morte, cada um a seu modo, procuraram tornar presente o passado. 0 filme seria, em resumo, uma tela transparente do passado. Ele traria a presença do passado. Os Inconfidentes toma partido da linguagem para mediar temporalidades distintas.

Em outro plano de significação, porém na mesma linha, as séries televisivas abertamente ficcionais tornam jocoso o tema histórico, considerando-o, contudo, seriamente tratado. Essa intencionalidade reverbera no espectador, evocando um gosto voyeur que se esgota de imediato ao assistir a série e não resulta em conhecimento. Pelo contrário, a repetição dessa teledramaturgia, quase normativa, enseja um espectador que tende a ficar desabilitado a ver e consumir uma produção televisiva vincada pelo conhecimento - a exemplo de programas de divulgação científica de excelência endereçada, em geral, aos canais da TV de sinal fechado." Ainda no âmbito dessas séries, cabe indagar mais essa relação entre uma narrativa histórica pertinente e coerente e o grande público que, a princípio, residiria no argumento factual, biográfico e anedótico, no intuito provável de ampliar ou garantir a audiência.

Esses filmes comentados são (re)vistos em sala de aula recorrentemente fazendo as vezes de material de apoio didático. Eles seguem dando margem à compreensão de que o passado assim transcorreu, contribuindo para a naturalização do tema da Independência, que esvazia suas experiências vividas. No que tange ao sistema escolar, quanto ao material didático e paradidático - que seguem sendo os maiores divulgadores do conhecimento histórico no Brasil -, impressiona a força dessa compreensão majoritária acerca da Independência, apesar do amplo programa nacional de avaliação do livro didático e paradidático sustentado pelo MEC. Sob hipótese, talvez a pesquisa exposta flagre a imensa dificuldade de desmontagem de um entendimento histórico a propósito da fundação da nação e a elaboração continuada de regimes de verdade históricos acerca da Independência mais próximos da produção acadêmica, e com capacidade de circular em amplos e diversos espaços públicos.

No todo, João Paulo Pimenta e sua equipe contribuem com uma abordagem e com um instrumental possiveis de serem replicados e reapropriados. Seria interessante fazer uma sondagem de opinião semelhante, a indagar em Cametá no Pará ou em Cachoeira na Bahia, entre outros lugares, as compreensões e recordações locais da Independência. Essa pesquisa em grupo, em seu transcorrer, implicou, entre outras atividades, um debate sobre o gerenciamento das atividades de cada um e do grupo, os usos da internet e da confiabilidade das informações, o levantamento e mapeamento das obras e seus espaços de repercussão e seus usos em São Paulo, uma frequência seletiva às publicações de divulgação da área de História, justamente quando ocorre no presente uma diversificação dos espaços de atuação profissional do historiador (museus, arquivos, TVs, parques, blogs, sites, centros de memória, museus comunitários, roteiros turísticos, ecomuseus, jardins, peças teatrais, cafés filosóficos, casas de saber, produção audiovisual e assim por diante), havendo uma aproximação entre divulgação do saber, entretenimento e conhecimento histórico. A pesquisa em grupo feita nesses moldes ajuda a formar profissionais em condições recentes, concorrendo para desenvolver uma reflexão, na graduação, sobre esse 
Sobre esta noção, baseio-me em: SENNET, Richard. O Artifice. Rio de Janeiro: Record, 2009; Juntos: os rituais, os prazeres e a política da cooperação. Rio de Janeiro: Record, 2013. profissional numa experiência de forte teor laboratorial. Nessa perspectiva teórico-metodológica, que enseja uma produção de conhecimento histórico com um marcante traço laboratorial, surgem agora experiências em equipe com objetivos, compromissos, resultados esperados e parciais apoiados pelo Estado, inclusive motivados por ele, que podem afetar essa história pública do conhecimento histórico. Com méritos e metas diversas, recordo o ProfHistória/CAPES, projeto de aproximação da Educação Básica e da PósGraduação em História que presume o intercâmbio entre elas em fase de implantação. Recordo também a Olimpiada Nacional em História do Brasil como programa de extensão para Ensino Médio e Fundamental, sediado na UNICAMP, que envolve em média 40 mil participantes a cada edição. Nessa perspectiva, a pesquisa apresentada aborda também a questão dos modos de produção contemporâneos do conhecimento histórico.

0 primeiro plano da pesquisa liderada por João Paulo Pimenta ocupa-se da discussão sobre as compreensões da Independência. Porém, num segundo plano, a pesquisa revela procedimentos de ensino-aprendizagem de forte caráter laboratorial operacionalizados durante a formação e na atuação do historiador com características especificas. Trata-se de perceber alguns procedimentos levados a cabo em equipe que asseguram os bons resultados dessa pesquisa. Indico alguns que a mim se sobressaem: as autoridades de saber não se restringem a uma pessoa ou ao professor, antes são compartilhadas e os envolvidos coproduzem o conhecimento; a tecnologia não se restringe à função econômica (no intuito de baratear a pesquisa, por exemplo), ela muito mais instrumentaliza o conhecimento efetivo em diversos espaços sociais- da entrevista ao audiovisual; a própria pesquisa procura explicitar seus procedimentos e arcabouço teórico, assinalando suas validades e limitações. Nessas condições do tempo presente, o debate historiográfico também pragmaticamente ${ }^{12}$ avança. 